\title{
Campus Connectedness and Its Relationship to Stress, Anxiety and Depression among Nepalese Undergraduate Nursing Students
}

\author{
Priscilla Samson (1) \\ Patan Academy of Health Sciences, School of Nursing and Midwifery, Kathmandu, Nepal \\ Email: talwar.ritu@gmail.com
}

How to cite this paper: Samson, P. (2021) Campus Connectedness and Its Relationship to Stress, Anxiety and Depression among Nepalese Undergraduate Nursing Students. Open Journal of Nursing, 11, 871-881.

https://doi.org/10.4236/ojn.2021.1110071

Received: September 10, 2021

Accepted: October 22, 2021

Published: October 25, 2021

Copyright $\odot 2021$ by author(s) and Scientific Research Publishing Inc. This work is licensed under the Creative Commons Attribution International License (CC BY 4.0).

http://creativecommons.org/licenses/by/4.0/

\section{(c) (i) Open Access}

\begin{abstract}
Background: Campus connectedness is a kind of social connectedness that determines the students' perception of their belonging to the other populace of the campus that includes students, teachers, administrators, and other staff. Campus connectedness plays a significant role in determining stress, anxiety, and depression among students. The purpose of the study was to examine the relationship of campus connectedness to stress, anxiety, and depression among nursing students. Methods: This cross-sectional analytical study was conducted among 680 undergraduate nursing students from nine nursing colleges affiliated with a university in Kathmandu Valley. Data were collected from June 1, 2018, through July 10, 2018. Depression, Anxiety, Stress Scale and Campus Connectedness Scale were used to collect data. The data were analyzed using Statistical Package for Social Sciences version 23. A one-way multivariate analysis of variance (MANOVA) test was used to examine the relationship of campus connectedness to stress, anxiety, and depression. Discriminant analysis was done as a follow-up procedure to MANOVA. Results: Students had moderate to extremely severe levels of depression (51.7\%), anxiety (72.9\%) and stress (47\%). High campus connectedness score was observed $(M=62.42 ; \mathrm{SD}=9.79)$. Statistically significant differences were found among the levels of campus connectedness on the outcome variables, Wilks' lambda $(\lambda)=0.90, F(3,676)=24.56, p<0.001$. Depression demonstrated the strongest relationship with the discriminant function. Conclusions: There was a significant relationship of campus connectedness to stress, anxiety, and depression. Despite the high level of campus connectedness, students had moderate to severe levels of stress, anxiety, and depression. The campus adminstration must take measures and efforts to provide conducive environment and counseling services for the wellbeing of their students.
\end{abstract}




\section{Keywords}

Anxiety, Belongingness, Campus Connectedness, Campus Connectedness Scale, Depression, DASS-21, Nursing Students, Stress

\section{Introduction}

Nursing education and training are highly challenging and demanding and, as a result, may cause a high prevalence of stress, anxiety, and depression among nursing students [1] [2]. Stress, anxiety, and depression may not only affect students' learning and clinical performance [3] but could also endanger the lives of patients under their nursing care. Nursing students may feel compelled to even discontinue the program [4]. Among the various determinants of stress, anxiety and depression, campus connectedness is a newer concept that has been derived from the concept of social connectedness [5] [6]. It has also been referred to as a sense of belonging in the literature [7]. Campus connectedness makes the students feel that they belong to the social environment that involves students, teachers, administrators, and other staff. Campus connectedness determines the students' perception of their belonging to the members of the campus [8].

The limited research done among college students has shown a significant negative relationship between campus connectedness and stress, anxiety, and depression [9] [10] [11] [12]. A series of studies conducted by Lee and his associates suggested a relationship between campus connectedness and psychological distress including anxiety and depression [5] [6] [13]. However, the number of studies done to establish the relationship between campus connectedness and stress, anxiety, and depression may fail to provide strong evidence.

Studies in Nepal reveals high levels of depression (37.8\% to $69.2 \%, N=332$ ) [14] [15] [16] and stress $(77.5 \%, N=169)$ among nursing students [17]. Similarly, limited literature is available on the relationship of campus connectedness with stress, anxiety, and depression among nursing students [18]. Nursing students need to have a high campus connectedness within the classroom and clinical environment so that they can approach faculty members and counselors at the time when they need to express their worries and anxieties [12] [19]. Thus, the aim of this study was to determine the level of campus connectedness and its relationship with stress, anxiety, and depression among nursing students.

\section{Methods}

\subsection{Design}

This was a cross-sectional correlational design to determine the relationship of campus connectedness with stress, anxiety, and depression.

\subsection{Population and Sampling}

The target population in this study included 1072 undergraduate Bachelor of 
Science (BSc.) in nursing students who were enrolled in fourteen colleges affiliated to the same university in Kathmandu valley, Nepal. The BSc. nursing program is a 4-year degree program that only enrolled female candidates at the time of data collection. Students from all the academic years were included in the study. Out of 14 colleges, only nine participated in the study that had altogether 744 students enrolled.

Convenience sampling was used to select participants for the study. Sample size was calculated using $\mathrm{G}^{*}$ Power 3.1 [20]. The Correlational studies require a large sample to obtain a true reflection of variables being measured [21]. Therefore, $744 \mathrm{BSc}$ nursing students were included; however, 682 participated in this study, which yielded a response rate of $91.7 \%$.

\subsection{Research Instruments}

Depression Anxiety Stress Scale (DASS)-21 by Lovibond and Lovibond [22] was used to assess the levels of stress, anxiety, and depression among nursing students. The instrument is a 4-point-Likert scale with seven items each for stress, anxiety, and depression. Each item has a statement with four response options to reflect the severity of stress, anxiety, and depression. The score responses start from 0 (did not apply to me at all), 1 (applied to me to some degree or some of the time), 2 (applied to me to a considerable degree or a good part of time), 3 (applied to me very much or most of the time). The subscale of stress comprises of seven items.

The score on DASS-S ranges from 0 to 21 that was multiplied by 2 to calculate the final score for Stress subscale, which is 42 . The cut-off score according to the severity of stress is Normal (0 - 14), Mild (15 - 18), Moderate (19-25), Severe (26 - 33), Extremely Severe (34+). The total score on DASS-A ranges from 0 to 21 , which was multiplied by 2 to make a total score of 42 . The cut-off scores from anxiety are: Normal (0 - 7), Mild (8 - 9), Moderate (10 - 14), Severe (15 19), Extremely Severe (20+). The score on DASS - D scale ranges from 0 to 21 , which was multiplied by 2 to make the total score of 42 . The recommended cut-offs scores for depression are: Normal (0 - 9), Mild (10 - 13), Moderate (14 20), Severe (21 - 27), Extremely Severe (28+).

Campus connectedness was measured by using Campus Connectedness Scale (CCS) [5] [23]. CCS is a-6-point-Likert scale comprising of 14 items. The rating response on this scale include $1=$ strongly disagree, $2=$ Disagree, $3=$ mildly disagree, $4=$ mildly agree, $5=$ agree, $6=$ strongly agree. The CCS score ranges from 14 to 84 . High scores on CCS reflect a stronger sense of campus connectedness. The test of reliability with Cronbach's alpha was 0.79 , whereas the initial validity of CSS had a Cronbach's alpha of 0.92 [23] (Lee \& Davis, 2000). The mean score was used as a cut off score for determining low and high connectedness in this study [6]. Mean score less than 62.42 was considered as low connectedness, whereas mean score of 62.42 or above was categorized as high connectedness. 


\subsection{Ethical Consideration}

The ethical approval was obtained from Nepal Health Research Council (NHRC Reg. no. 280/2018). The participants were informed that they can opt out from participating in the study if they do not want to participate. It was also clarified that opting out from the study will not affect their academic evaluation in any way. No identifying information was requested on the survey or demographic data sheet. Students from the same college as the researcher were excluded to avoid bias.

\subsection{Data Collection Procedure}

Data were collected from June 1, 2018, through July 10, 2018, using self-administered questionnaires after obtaining consent from the participants. The researcher in consultation with the Principals of the Nursing Colleges scheduled a visit to each school for personally collect the data for this study. A total number of students who consented for participating in the study were 682, of which two participants did not complete the survey forms and were excluded from the study.

\subsection{Data Analysis}

The descriptive statistics was used to describe the sociodemographic variables, levels of stress, anxiety, depression, and level of campus connectedness. The tests included frequencies, means, and standard deviations. MANOVA test was used to examine the correlation between campus connectedness and stress, anxiety, depression. In this study, campus connectedness was the predictor variable whereas, the outcome variables were stress, anxiety and depression. Discriminant test was done as a follow up procedure for significant $F$ value for MANOVA. The data were entered into IBM SPSS 23 for storage and analysis. Entry of data was double-checked for completion and accuracy.

\section{Results}

The nursing students who participated in this study were between the ages of 18 and $27(\mathrm{M}=20.29 \pm \mathrm{SD}=1.65)$. Since, in Nepal, the B.Sc. Nursing program is only offered to the female candidates, all participants in this study were females. Majority of participants $(83.5 \%, n=568)$ were living in an urban area before enrolling for the program. Most parents $(88.8 \%, n=604)$ paid the fee for the students who participated in this study (Table 1). In all four academic years almost similar number of students were enrolled (Figure 1).

More than half of the participants $(54.41 \%)$ had high campus connectedness (Table 2).

Participants had moderate to extremely severe levels of depression $(51.7 \%, n=$ $350)$, anxiety $(72.9 \%, n=496)$, and stress $(47 \%, n=319)$ at the time of data collection. A mild level of depression, anxiety, and stress were found among $17.9 \%$ $(n=122), 8.4 \%(n=57)$ and $28.4 \%(n=193)$ students respectively. The mean values of stress, anxiety, and depression are listed in Table 3. 
Table 1. Participants' socio-demographic data $(N=680)$.

\begin{tabular}{lcc}
\hline \multicolumn{1}{c}{ Characteristics } & Frequency $(n)$ & Percentage $(\%)$ \\
\hline Age $(\mathrm{M}=20.29, \mathrm{SD}=1.65)$ & & \\
\hline Marital status & & \\
$\quad$ Single & 656 & 96.5 \\
$\quad$ Married & 21 & 3.1 \\
$\quad$ Divorced & 3 & 0.4 \\
\hline Residence prior to joining campus & & \\
$\quad$ Rural & 112 & 16.5 \\
$\quad$ Urban & 568 & 83.5 \\
\hline Arrangement for paying college fee & & \\
$\quad$ Scholarship & 57 & 8.4 \\
$\quad$ Education loan & 19 & 2.8 \\
$\quad$ Parents/Relatives & 604 & 88.8 \\
\hline
\end{tabular}

Table 2. Participants' level of campus connectedness $(N=680)$.

\begin{tabular}{ccccc}
\hline Campus Connectedness & Frequency & Percentage & Mean & Standard Deviation \\
\hline Low & 310 & 45.59 & 62.42 & 9.79 \\
High & 370 & 54.41 & & \\
\hline
\end{tabular}

Table 3. Mean score and standard deviation for outcome variables: stress, anxiety, depression.

\begin{tabular}{ccc}
\hline Outcome Variable & Mean & Standard Deviation \\
\hline Stress & 9.52 & 4.14 \\
Anxiety & 7.67 & 4.25 \\
Depression & 7.48 & 4.87 \\
Total DASS $^{\text {a }}$ & 24.67 & 11.75 \\
\hline
\end{tabular}

${ }^{a}$ Depression, Anxiety, Stress Scale.

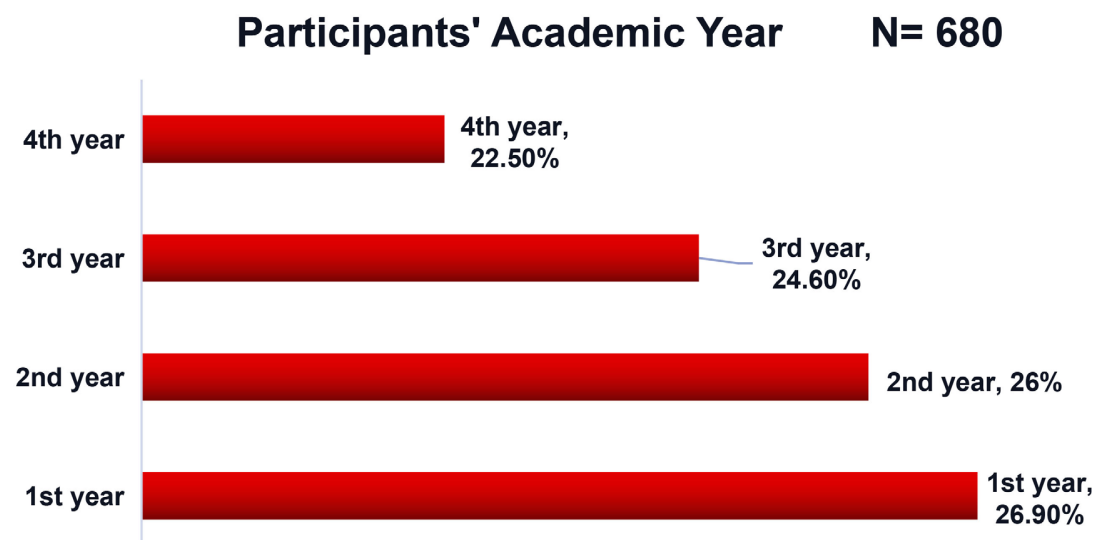

Figure 1. Participants' academic year.

Table 4 shows the result of a one-way MANOVA that determined the effect of two levels of campus connectedness (low and high) on the three outcome variables, 
Table 4. Multivariate test for campus connectedness.

\begin{tabular}{ccccccc}
\hline Effect Wilk's Lambda & Value & $F$ & Hypothesis df & Error df & Significant & $\begin{array}{c}\text { Partial Eta } \\
\text { Squared }\end{array}$ \\
\hline Intercept & 0.143 & 1353.677 & 3.000 & 676.000 & 0.000 & 0.857 \\
Campus Connectedness & 0.902 & 24.558 & 3.000 & 676.000 & 0.000 & 0.098 \\
\hline
\end{tabular}

the stress, anxiety, and depression. Statistically significant differences were found among the levels of campus connectedness on the outcome variables, Wilks' lambda $(\lambda)=0.90, F(3,676)=24.56, p<0.001$.

Table 5 shows the discriminant analysis to determine whether stress, anxiety, and depression can predict campus connectedness. The overall Wilks' lambda was significant, $\lambda=0.90(3, N=680)=69.98, p<0.001$ indicating that overall, the predictors variables, stress, anxiety, and depression differentiated across the two levels of campus connectedness. Function 1 had an eigenvalue of 0.109 and a canonical correlation of 0.313 (Table 4). By squaring the canonical correlation for the discriminant function $(0.3132=0.09)$, the eta square on the discriminant function was obtained. Accordingly, $9 \%$ of the variability of the scores for the discriminant function was accounted for by differences among the two campus connectedness groups. The eta square value of 0.09 indicated a moderate effect size.

The coefficients for the discriminant functions are shown in Table 5. Discriminant function was named by determining which variable is most strongly related to it. The discriminant function showed a positive relationship with stress and depression and a negative relationship with anxiety. Based on the with-in groups relationship between the predictors, stress, anxiety, depression, and the discriminant functions in Structure Matrix (Table 6), depression demonstrated the strongest relationship with the discriminant function. Thus, discriminant function was named as depression.

\section{Discussion}

Out of 680 participants in this study, most students reported moderate to extremely severe level of anxiety (72\%) followed by depression (51\%), and stress (47\%). The findings of this study concur with Basu et al. [24] who found that students had moderate to extremely severe levels of anxiety (56.6\%), followed by depression (33.3\%), and stress (23.26\%). In a similar study conducted in Hong Kong, nursing students reported moderate to extremely severe anxiety (39.9\%), depression (24.3\%), and stress (20\%) [7]. Ratnayake and Ekanayake [25] reported different findings indicating highest prevalence of moderate to extreme level of stress (64\%) followed by anxiety (50\%) and depression (39\%) among nursing students.

More than half of the participants reported a high level of campus connectedness which concurs with research conducted among students from Australia, United States, and Hong Kong reporting a high level of campus connectedness. 
Table 5. Tests of significance and strength-of-relationship statistics for campus connectedness.

\begin{tabular}{ccccc}
\hline \multicolumn{5}{c}{ Eigenvalues } \\
\hline \multirow{2}{*}{ Function } & Eigenvalue & \% of Variance & Cumulative \% & Canonical correlation \\
\hline 1 & $0.109^{\mathrm{a}}$ & 100.0 & 100.0 & 0.313 \\
\hline
\end{tabular}

1. First 1 canonical discriminant functions were used in the analysis.

\begin{tabular}{ccccc}
\hline \multicolumn{5}{c}{ Wilks' Lambda } \\
\hline Test of Function(s) & Wilks' Lambda & Chi-square & df & Sig. \\
\hline 1 & 0.902 & 69.982 & 3 & 0.000 \\
\hline
\end{tabular}

Table 6. Coefficients for discriminant functions and the pooled with-in group's correlations for campus connectedness.

\begin{tabular}{cc}
\hline & Standardized Canonical Discriminant Function Coefficient \\
\hline Stress & Function \\
Anxiety & 0.485 \\
Depression & -0.026 \\
& 0.606 \\
\hline & Structure Matrix \\
\hline Depression & Function \\
Stress & 1 \\
Anxiety & 0.948 \\
& 0.914 \\
& 0.669 \\
\hline
\end{tabular}

Bales et al. [9] also reported high levels of connectedness in the sample of female university students. The reason for the high level of connectedness could be the familiarity that students have with the campus environment. Contrary to this finding, Lykes and Kemmelmeier found students from Asian background had lower levels of campus connectedness [26]. Undergraduate students begin learning fundamental nursing skills during their clinical placement and spend most of their time in clinical settings [27]. Therefore, it is important that they feel connected with their clinical environment. This study focused on campus connectedness, and thus the interpretation could differ from that of clinical placement connectedness [27] [28]. Therefore, clinical placement connectedness should be included in future studies for the students in Nepal.

The results of this study showed statistically significant relationship between campus connectedness and stress, anxiety, and depression. This result is consistent with the findings from previous research which showed a significant inverse relationship between connectedness and stress [28] [29]. Similarly, two different 
studies [30] [31] evidenced a significant relationship between campus connectedness and depression. On the other hand, findings in the study by Eckberg et al. [10] showed no significant relationship between campus connectedness and depression. Eckberg et al. [10] suggested that higher level of campus connectedness significantly predicted lower levels of anxiety.

Bales et al. [9] argued that there may be cross-cultural differences that may influence the relationship between campus connectedness and psychological distress. However, the findings of their study did not support the research hypothesis about cross-cultural differences among university students from three different countries but revealed a positive relationship between connectedness and psychological well-being which they defined as lower levels of stress, anxiety, and depression. In a study done among Turkish undergraduate students, it was found that students with high campus connectedness had low levels of perceived stress that suggested better life satisfaction [30].

Similarly, a hierarchical regression revealed that a higher-level of campus connectedness significantly predicted lower levels of anxiety symptoms, while there was no significant relationship between a high level of campus connectedness and depression [10]. Pidgeon et al. [30] suggested campus connectedness has the buffering effect on the relationship between stress and depression. Furthermore, Stebleton et al. [31] created strong evidence on the relationship between campus connectedness and symptoms of stress and depression in their large-scale survey $(N=145,150$, out of which $\mathrm{n}=58,017$ responded $(40 \%))$ conducted among first-generation university students. In their study, students with a high sense of campus connectedness experienced fewer symptoms of stress and depression.

Discriminant analysis also examined group correlation between predictors stress, anxiety, depression, discriminant factor, and campus connectedness which demonstrated that depression had the strongest relationship with the discriminant factor. This indicated that depression was the most significant variable to differentiate groups of campus connectedness. Furthermore, the discriminant function showed a positive relationship with stress and depression and a negative relationship with anxiety. There were no studies found with discriminant analysis which could support these findings.

The cross-sectional approach limits data collection at one point in time. The study included nursing students from all the four academic years. The way they perceived stress, anxiety, depression may vary according to their current academic year. Therefore, a longitudinal approach could be better to compare the variance based on the academic year. The post-hoc test can be conducted on the predictor variable to compare each group to all other group which could not be done in this study as it requires a predictor variable with more than two groups, whereas, in this study, predictor variables had only two groups.

\section{Conclusion}

This study found a significant relationship of campus connectedness with stress, 
anxiety, and depression. Despite showing high levels of campus connectedness most of the sampled students experienced moderate to extremely severe levels of stress, anxiety, and depression. Increasing levels of depression may induce self-injury or suicidal tendency in students. Hence, the colleges should take the initiative to introduce and implement services such as periodic mental health screening and counseling facilities that will enhance the mental health of the students. Nursing students will go on to take up the nursing profession in due course of time, and this profession is prone to handling stressful or anxiety-filled situations. Therefore, the college administrators and the faculty need to work in sync with the management in helping students with stress and anxiety management, which will empower the students in becoming mentally healthy nursing professionals. Finally, the findings in this study have contributed to the nursing literature related to campus connectedness and its relationship with stress, anxiety, and depression among nursing students in Nepal.

\section{Acknowledgements}

The author expresses sincere thanks to all the students from nine colleges who participated in this study.

\section{Conflicts of Interest}

The author declares no conflicts of interest regarding the publication of this paper.

\section{References}

[1] Bilgel, N. and Bayram, N. (2014) The Epidemiology of Depression, Anxiety, Stress, and Anger in Turkish High School Students. British Journal of Education, Society \& Behavioural Science, 4, 1153-1170. https://doi.org/10.9734/BJESBS/2014/8733

[2] Patterson, S.L. (2016) The Effect of Emotional Freedom Technique on Stress and Anxiety in Nursing Students: A Pilot Study. Nurse Education Today, 40, 104-110. https://doi.org/10.1016/j.nedt.2016.02.003

[3] Chernomas, W.M. and Shapiro, C. (2013) Stress, Depression, and Anxiety among Undergraduate Nursing Students. International Journal of Nursing Education Scholarship, 10, 255-266. https://doi.org/10.1515/ijnes-2012-0032

[4] Shelton, E.N. (2012) A Model of Nursing Student Retention. International Journal of Nursing Education Scholarship, 9, 1-16. https://doi.org/10.1515/1548-923X.2334

[5] Lee, R.M., Keough, K.A. and Sexton, J.D. (2002) Social Connectedness, Social Appraisal, and Perceived Stress in College Women and Men. Journal of Counseling \& Development, 80, 355-361.https://doi.org/10.1002/j.1556-6678.2002.tb00200.x

[6] Lee, R.M. and Robbins, S.B. (1995) Measuring Belongingness: The Social Connectedness and the Social Assurance Scales. Journal of Counseling Psychology, 42, 232-241. https://psycnet.apa.org/doi/10.1037/0022-0167.42.2.232

[7] Cheung, T., Wong, S.Y., Wong, K.Y., Law, L.Y., Ng, K., Tong, M.K., Yip, P.S.F., et al. (2016) Depression, Anxiety, and Symptoms of Stress among Baccalaureate Nursing Students in Hong Kong: A Cross-Sectional Study. International Journal of 
Environmental Research and Public Health, 13, 779-804. https://doi.org/10.3390/ijerph13080779

[8] Agu, N., Omenyi, A. and Odimegwu, C. (2010) An Assessment of Students' Connectedness in Tertiary Institutions in Anambra State of Nigeria. Educational Research and Reviews, 5, 90-98.

[9] Bales, T.S., Pidgeon, A.M., Lo, B.C.Y., Stapleton, P. and Magyar, H.B. (2015) Cross-Cultural Differences in Coping, Connectedness and Psychological Distress among University Students. International Journal for Innovation Education and Research, 3, 114-125. https://doi.org/10.31686/ijier.vol3.iss2.318

[10] Eckberg, N., Pidgeon, A.M. and Magyar, H. (2017) Examining the Psychosocial and Academic Factors Predicting Depression and Anxiety Symptomology across First-Year and Later-Year University Students. European Scientific Journal, 13, 1-16. https://doi.org/10.19044/esj.2017.v13n17p1

[11] Laux, D., Luse, A. and Mennecke, B.E. (2016) Collaboration, Connectedness, and Community: An Examination of Factors Influencing Student Persistence in Vertical Communities. Computers in Human Behavior, 57, 452-464. https://doi.org/10.1016/j.chb.2015.12.046

[12] Samuolis, J., Griffin, K., Mason, M.J. and Dekraker, N. (2017) Connectedness to Campus and Likelihood of Help-Seeking for Suicidality among College Women. Journal of College Student Psychotherapy, 31, 238-246. https://doi.org/10.1080/87568225.2017.1312176

[13] Lee, R.M., Dean, B.L. and Jung, K.R. (2008) Social Connectedness, Extraversion, and Subjective Well-Being: Testing a Mediation Model. Personality and Individual Differences, 45, 414-419. https://doi.org/10.1016/j.paid.2008.05.017

[14] Paudel, S., Gautam, H., Adhikari, C. and Yadav, D.K. (2020) Depression, Anxiety and Stress among the Undergraduate Students of Pokhara Metropolitan, Nepal. Journal of Nepal Research Council, 18, 27-34. https://doi.org/10.33314/jnhrc.v18i1.2189

[15] Risal, A., Sanjel, S. and Sharma, P.P. (2016) Study of Depression among the Nursing Students in a University Medical College of Nepal. Kathmandu University Medical Journal, 14, 264-268. https://pubmed.ncbi.nlm.nih.gov/28814691/

[16] Sigdel, A. and Pokharel, P. (2015) Prevalence of Depression among Certificate and Nursing Students of Chitwan District, Nepal. Journal of Nepal Public Association, 6, 8-12. https://nepha.org.np/wp-content/uploads/2021/02/JNEPHA-VOLUME-6-ISSUE-1NO-6-JAN-JUNE-2014Archu.pdf\#page $=8$

[17] Shrestha, S. and Lama, R. (2014) Stress/Stressors as Perceived by Nepalese Nursing Students. International Journal of Nursing Research and Practice, 1, 5-9.

https://www.researchgate.net/profile/Sandhya_Shrestha2/publication/337949710_St ress_and_strors_perceived_by_nepalese_nursing_students/links/5e0f4195a6fdcc283 7536ec0/Stress-and-stressors-perceived-by-nepalese-nursing-students.pdf

[18] Horgan, A., Sweeney, J., Behan, L. and McCarthy, G. (2016) Depressive Symptoms, College Adjustments and Peer Support among Undergraduate Nursing and Midwifery Students. Journal of Advanced Nursing, 72, 3081-3092.

https://doi.org/10.1111/jan.13074

[19] Dunbar, H. and Carter, B. (2017) A Sense of Belonging: The Importance of Fostering Student Nurses' Affective Bonds. Journal of Child Health Care, 2, 367-369. https://doi.org/10.1177/1367493517739977

[20] Erdfelder, E., Faul, F. and Buchner, A. (1996) GPower: A General Power Analysis 
Program. Behavior Research Methods, Instruments, \& Computer, 28, 1-11. https://doi.org/10.3758/BF03203630

[21] Houser, J. (2015) Nursing Research: Reading, Using, and Creating Evidence. 3rd Edition, Jones \& Bartlett Learning, Burlington.

[22] Lovibond, S.H. and Lovibond, P.F. (1995) Manual for Depression Anxiety Stress Scales. 2nd Edition, Psychology Foundation, Sydney.

[23] Lee, R.M. and Davis, C. (2000) Cultural Orientation, Past Multicultural Experience, and a Sense of Belonging on Campus for Asian American College Students. Journal of College Student Development, 41, 110-115.

[24] Basu, M., Sinha, D., Ahamed, A., Chatterjee, S. and Misra, R.N. (2016) Depression, Anxiety, Stress among Nursing Students of Kolkata: A Cross Sectional Study. Journal of Preventive Medicine and Holistic Health, 2, 54-60.

[25] Rathnayake, S. and Ekanayaka, J. (2016) Depression, Anxiety, and Stress among Undergraduate Nursing Students in a Public University in Sri Lanka. International Journal of Caring Sciences, 9, 1020-1032.

[26] Lykes, V.A. and Kemmelmeier, M. (2013) What Predicts Loneliness? Cultural Difference between Individualistic and Collectivistic Societies in Europe. Journal of Cross-Cultural Psychology, 45, 468-490.

https://doi.org/10.1177\%2F0022022113509881

[27] Honda, K., Levett-Jones, T., Stone, T. and Maguire, J. (2016) Japanese Nursing Students' Sense of Belonging: A Story of Uchi (Insider) and Soto (Outsider). Nurse Education in Practice, 20, 85-92. https://doi.org/10.1016/j.nepr.2016.07.004

[28] Grobecker, P.A. (2016) A Sense of Belonging and Perceived Stress among Baccalaureate Nursing Students in Clinical Placements. Nurse Education Today, 36, 178-183. https://doi.org/10.1016/j.nedt.2015.09.015

[29] Civitci, A. (2015) Perceived Stress and Life Satisfaction in College Students: Belonging and Extracurricular Participation as Moderators. Procedia-Social and Behavioral Sciences, 205, 271-281. https://doi.org/10.1016/j.sbspro.2015.09.077

[30] Pidgeon, A.M., McGrath, S., Magya, H.B., Stapleton, P. and Lo, B.C.Y. (2014) Psychosocial Moderators of Perceived Stress, Anxiety, and Depression in University Students: An International Study. Open Journal of Social Sciences, 2, 23-31. http://dx.doi.org/10.4236/jss.2014.211004

[31] Stebleton, M.J., Soria, K.M. and Huesman, R.L. (2014) First-Generation Students' Sense of Belonging, Mental Health, and Use of Counseling Services at Public Research Universities. Journal of Collage Counseling, 17, 6-20. https://doi.org/10.1002/j.2161-1882.2014.00044.x 